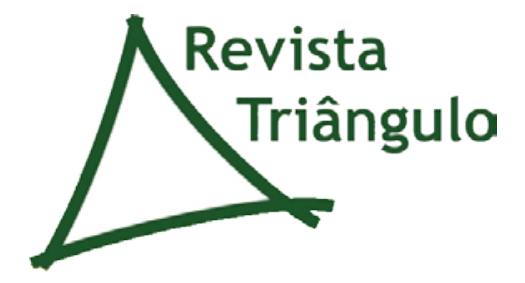

Uberaba, v. 5, n. 1, p. 87-105, jan./jun. 2012. ISSN: 2175-1609

\title{
O SENTIDO DO DEVIR NA CRIAÇÃO ARTÍSTICA DE PABLO PICASSO: REFLEXÕES PARA A EDUCAÇÃO
}

\section{THE MEANING OF COMING TO BE IN THE PABLO PICASSO'S ARTISTIC CREATION: REFLECTIONS ON EDUCATION}

\author{
Sueli Teresinha Abreu-Bernardes ${ }^{1}$, Leonora de Abreu Bernardes ${ }^{2}$
}

\footnotetext{
${ }^{1}$ Doutora em Educação pela UFG. Professora do Programa de Pós-Graduação em Educação da Universidade de Uberaba, pesquisadora da Rede de Pesquisadores sobre o Professor do Centro-Oeste - REDECENTRO e do Observatório Internacional de la Profesión Docente - OBIPD, da Universidade de Barcelona. E-mail: abreubernardes@terra.com.br

${ }^{2}$ Aluna do Curso de Direito, participante da Rede de Pesquisadores sobre o Professor - REDECENTRO. E-mail: leonora.bernardes20@gmail.com
} 


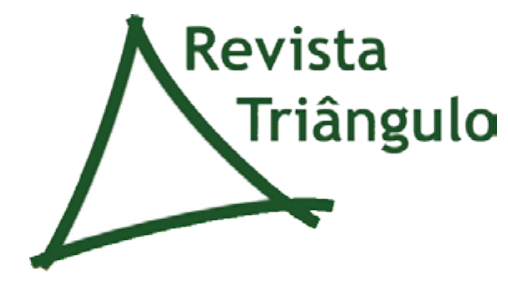

Uberaba, v. 5, n. 1, p. 87-105, jan./jun. 2012. ISSN: 2175-1609

\title{
RESUMO
}

Sob um olhar fenomenológico, expressam-se reflexões em torno da obra de Pablo Picasso. A partir da observação do constante vir-a-ser da criação artística do mestre espanhol, infere-se que permanece uma unidade: o retratar da condição humana. O exercício do pensamento é realizado na perspectiva teórica da fenomenologia bachelardiana ao pensar a arte e, igualmente, a educação.

Palavras-chave: Arte. Pablo Picasso. Fenomenologia Bachelardiana. Educação.

\begin{abstract}
Under a phenomenological point of view, the reflections on the work of Pablo Picasso are expressed. From the observation of the constant come to be of the Spanish master's artistic creation, it is inferred that a unit remains: the portrayal of the human condition. The exercise of thought is accomplished in the theoretical perspective of the Bachelardian phenomenology when thinking about art and also education.
\end{abstract}

Keywords: Art. Pablo Picasso. Phenomenology Bachelard. Education. 


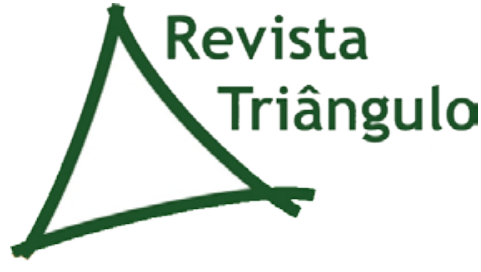

Uberaba, v. 5, n. 1, p. 87-105, jan./jun. 2012. ISSN: 2175-1609

\section{O SENTIDO DO DEVIR NA CRIAÇÃO ARTÍSTICA DE PABLO PICASSO: REFLEXÕES PARA A EDUCAÇÃO ${ }^{i}$}

“A minha vida eu a vivo em círculos crescentes Sobre as coisas, alto no ar. Não completarei o último, provavelmente,

Mesmo assim irei tentar. Giro à volta de Deus, a torre das idades, E giro há milênios, tantos... Não sei ainda o que sou, falcão, tempestade, Ou um grande, um grande canto.” Rainer Maria Rilke

Nesse poema, o lírico alemão descreve a busca de um sentido e de uma identidade de vida. A poesia fala dos movimentos alteados e das visões desiguais sobre o próprio existir. Lembrando o pensamento heraclitiano, os versos de Rilke buscam a unidade no vir-a-ser.

Esse processo de busca de si mesmo não se desfaz no enlevo da travessia, pois trabalha com o encantamento desperto e dirigido para o encontro. Essa travessia é também uma luta silenciosa contra direções que se tentam impor a uma luta que se refaz na opção da trilha a seguir. Na verdade, não há caminho, pois o caminho é feito na medida em que se segue ao longo dele, na procura do eu mesmo. O processo de tomada de consciência dessa busca passa por diversos percalços, retrocessos, por lugares e tempos imprevisíveis, num mundo de sonhos despertados. Não é ao acaso que “Grande Sertão: Veredas” (ROSA, 2001), começando com a palavra "nonada”, termina com a palavra "travessia”.

Porém, é preciso estar atento ao que se encontra nesse devir. Quem partilha de nossos sonhos, de nossas dúvidas? Quem vive uma experiência que possa elucidar a nossa? Seria a ciência, a filosofia, a arte? 


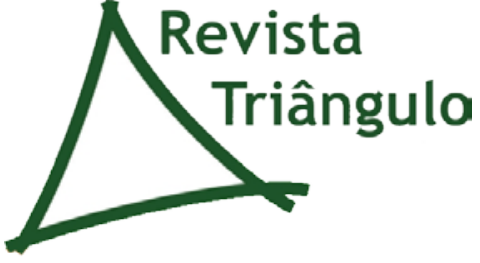

Uberaba, v. 5, n. 1, p. 87-105, jan./jun. 2012. ISSN: 2175-1609

\section{A CRIAÇÃO ARTÍSTICA E OS CONCEITOS}

Em ciclos de vida e círculos de aproximação à ciência, à filosofia e à arte, sempre presentes em meu percurso, transito das teorias para o lirismo poético, do rigor dos conceitos para a transgressão da criação artística. Ora dialogo com as ideias dos pensadores de ontem e de hoje, ora converso com as metáforas do real. Confesso que procuro sempre o poeta, além do cientista e do filósofo. Mas continuamente pergunto a mim mesma: tem de ser assim mesmo? Ou a educadora de fala pedagógica ou a professora devaneante? “Ou isto ou aquilo”, como expressam as metáforas dos versos de Cecília Meireles?

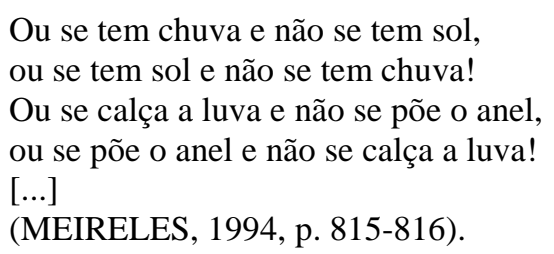

Esse pensamento inquieto tem estado presente em minha vida como docente e pesquisadora. A separação entre a criação artística e a produção intelectual sempre me pareceu destoante. Ou dar vazão à sensibilidade ou dedicar-me à ciência e à filosofia pareciam-me uma alternância falsa, pois entendia os dois domínios como resultantes de uma convivência de um com o outro na mesma tessitura da vida.

Tal reflexão aproxima-se do entendimento do conceito de "experiência alargada”, expresso por Maurice Merleau-Ponty no ensaio “De Mauss a Claude Lévi-Strauss” (1980, p. 199-200) em que, entre outros temas, o autor analisa o ideário antropológico que elege como seu objeto a investigação do “Outro e do Mesmo, da Diferença e da Identidade” e, assim, questiona "a racionalidade estreita posta pelo saber ocidental". Ao propor a alteridade como objeto, Merleau-Ponty considera que a antropologia provê um instrumento para o alargamento da razão, para a coexistência dos considerados incompatíveis, para um universo formado por interações de complementaridade. Penso que as relações com a cultura conduzem a uma crítica dirigida à racionalidade e possibilitam a criação de um espaço de encontro de diferentes saberes; no meu caso, as vivências do campo poético e os estudos filosóficos e pedagógicos. 


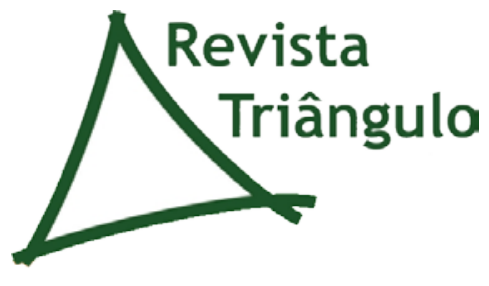

Uberaba, v. 5, n. 1, p. 87-105, jan./jun. 2012. ISSN: 2175-1609

As imagens de deleite que a apreciação artística sempre me proporcionou foram se transformando em perguntas que as investigações desenvolvidas procuraram mais que responder, fundamentar. Um eu autopoiético ${ }^{\mathrm{ii}}$ é, talvez, a expressão mais próxima ao sentido de inteireza que busco em minha travessia.

Penso que a compreensão do sentido das questões presentes neste artigo supõe um desvelamento da construção de uma identidade que assim se expressa: uma pesquisadora que se dedica às relações entre a arte e a educação com vistas ao desenvolvimento da sensibilidade na formação humana. Assim, trago lembranças de uma procura de convívio com a beleza que as diferentes linguagens artísticas sempre me proporcionaram.

É preciso reconhecer que muitas de nossas recordações, ou mesmo de nossas ideias, são inspiradas no convívio entre os círculos de vida. Com o fluir do tempo, elas passam a ser nossa biografia, acompanham nossa vida e são enriquecidas por novas experiências e diálogos. Assim, detenho-me em lembranças. Elas me parecem tão minhas que ficaria surpresa se me dissessem o ponto exato de sua entrada em minha vida. E se elas "às vezes afloram ou emergem, quase sempre são uma tarefa, uma paciente reconstituição” (BOSI, 1994, p. 39).

Medito, ainda, quanto ao sentido da liberdade do agir humano, pois embora vivamos mergulhados nas circunstâncias, criamos ao desvelar a realidade e ao ir além dos fatos. Assim, procuro elaborar outro pensamento ao relatar o conhecimento construído.

Reflito de igual modo a dimensão histórica, que é a capacidade da consciência de ligar os fatos numa sucessão temporal. Procuro ver o que seja a origem, o que seja o envolver, o que seja a plenitude, eventualmente uma decadência, o renascer, e um crescer, e um envolver, e novamente uma plenitude, e uma decadência e um renascer dos acontecimentos. Observo que a vida humana é sempre um curso, um discurso, um correr, um discorrer, um fluir, um andar. O homem é travessia. Travessia no sentido do dinâmico da vida, da dialética da vida. Se não tivermos essa visão heraclitiana em sua genealogia, ficaremos ancorados no passado e perderemos o senso da esperança e, ao mesmo tempo, o sentido da futuridade. Nessa acepção, penso a minha trajetória num sentido agostiniano. Trago, pois, o presente das coisas passadas (a memória), o presente das coisas presentes (a visão) e o presente das coisas futuras (a 


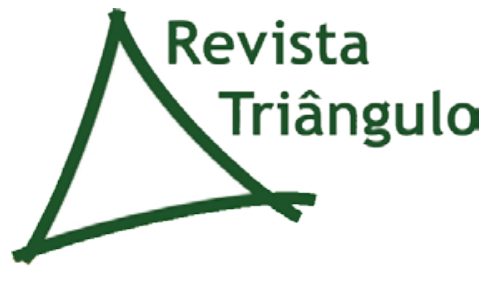

Uberaba, v. 5, n. 1, p. 87-105, jan./jun. 2012. ISSN: 2175-1609

expectativa). E reflito, ainda: no meu agora, tenho o outrora, no meu presente, possuo o antigamente.

O que, ao longo do tempo, li, pensei e senti, a prática acadêmica e o diálogo com autores, atores, poetas, escultores, músicos, cantores e tecelões compõe uma trajetória comum a muitos de uma geração contemporânea às mesmas condições históricas em que vivi. Hoje, emergem lembranças de movimentos, de leituras de mundo e de aprendizagens.

Por que, na construção deste texto, parto do significado da própria experiência vivida como pesquisadora das questões sobre arte e educação?

Penso que este estudo parte da compreensão do existir e não de conceitos ou definições, e é uma compreensão voltada para os significados do perceber, isto é, para o sentido das percepções que o sujeito tem daquilo que está sendo pesquisado. Essa compreensão, que orienta o investigador a apreender aquilo que irá estudar, é oriunda da volta ao mundo da vida. O pesquisador conduz suas leituras a partir de uma interrogação acerca de um fenômeno vivenciado pelo sujeito. Essa vivência expressa como foi engendrado um desejo de investigar e o início de construção de um conhecimento que, no caso deste artigo, é pensar a arte e a educação.

A atitude de não partir do zero, mas de um continuum de reflexões, justifico-a, ainda, com Gaston Bachelard, quando ele afirma:

a ideia de partir de zero para fundamentar e aumentar o próprio acervo só pode vingar em culturas de simples justaposição, em que um fato conhecido é imediatamente uma riqueza. Mas, diante do mistério do real, a alma não pode, por decreto, tornar-se ingênua. É impossível anular, de um só golpe, todos os conhecimentos habituais (BACHELARD, 1996b, p. 17-18).

A ingenuidade seria acreditar que o novo se constituiria na investigação que deu origem a este texto, nas reflexões do corpo teórico escolhido, numa equivocada pretensão de objetividade. Por conseguinte, uma reflexão como esta, em que me aproximo do método fenomenológico bachelardiano, encaminha-se, inicialmente, na direção da experiência do eu investigador, uma vez que tal método enfatiza a dimensão existencial do viver humano.

Comentando a fenomenologia que propõe, Gaston Bachelard (1996a, p. 1-2) afirma que esse método “obriga-nos a um retorno sistemático a nós mesmos, a um esforço de clareza na tomada de consciência”, e se “o filósofo [...] por vezes tem a pretensão de estar começando 


\section{Revista
Triângulo}

Uberaba, v. 5, n. 1, p. 87-105, jan./jun. 2012. ISSN: 2175-1609

tudo [...], porém, ele está continuando”. Buscar os primeiros esboços de um pensamento em construção significa ter a consciência do processo, ter a compreensão do aspecto subjetivo de um conhecimento que se constrói.

Ao falar de experiência, a que conceito me refiro? É sabido que há uma polissemia de sentidos nessa palavra, utilizados para nomear diversas situações. Neste texto, emprego a acepção de experiência tal como a interpreto desde Walter Benjamin (1994) e nas palavras de Jorge Larrosa (2002) $)^{\mathrm{iii}}$, as quais me conduzem ao fenomenólogo Martin Heidegger (1987).

A experiência se expressa com densidade ideológica e posicionamento político, pois não é uma palavra aleatória, mas um conceito essencial no corpo teórico de Walter Benjamin. O filósofo de Berlim descreve o conceito de experiência a partir de sua falta (BENJAMIN, 1994, p.114 e ss). Para ele, o desaparecimento origina-se da descontinuidade da tradição humana de transmissão de uma palavra de uma geração para outra. Essa carência provoca a perda dos modos tradicionais de narrativa que têm sua origem nessa transmissibilidade. A arte de narrar tornou-se incomum porque relata a comunicação de uma experiência que já não é plausível, pois não existem mais condições de a vivenciarmos no mundo moderno, o qual é excessivamente ligado à informação.

No artigo “Notas sobre a experiência e o saber de experiência”, Jorge Larrosa (2002, p. 21) acrescenta algo às reflexões de Benjamin, ao descrever o conceito: "a experiência é o que nos passa, o que nos acontece, o que nos toca. Não o que se passa, não o que acontece, ou o que toca”. Muitas coisas ocorrem no dia a dia, mas quase nada nos move, nos impressiona. Um dos motivos para isso é a passagem fugaz, efêmera, que impede a vinculação expressiva entre acontecimentos e embaraça também a memória, pois não há experiência para ser lembrada. Este é o aspecto que ressalto: as recordações supõem o ser estimulado pelo acontecimento, e é desse modo que identifico as memórias da investigação efetivada. Cada interação com a arte provocava em mim novos pensamentos e intuições sobre o sentido da criação artística. E, hoje, o que vivenciei me interroga e me desafia na invenção de novas ideias.

Larrosa leva-me a um fenomenólogo que assim escreve:

[...] fazer uma experiência com algo significa que algo nos acontece, nos alcança, que se apodera de nós, que nos tomba e nos transforma. Algo se faz, advém, tem 


\section{$\bigwedge_{\text {Riiângulo }}^{\text {Revista }}$}

Uberaba, v. 5, n. 1, p. 87-105, jan./jun. 2012. ISSN: 2175-1609

lugar [...] Fazer uma experiência [...] quer dizer, portanto, nos deixarmos abordar pela interpelação da palavra, entrando e submetendo-nos a ela. [...] podemos ser assim transformados por tais experiências, de um dia para o outro ou no transcurso do tempo (HEIDEGGER, 1987, p. 141).

O sujeito da experiência é um sujeito envolvido, porque ele se apodera daquilo de que faz experiência. Além disso, como se lê nas últimas palavras desse recorte selecionado na obra de Heidegger, outra dimensão primordial da experiência é a sua capacidade de formar ou de transformar o sujeito. Ao nos acontecer, ao nos tocar, ao se apoderar de nós, a experiência nos transforma. Larrosa (2002, p. 26) diz: "somente o sujeito da experiência está, portanto, aberto à sua própria [formação e] transformação”. Assim, as experiências de uma pesquisa realizada permanecem em mim, interagem através de mim e se intercomunicam, pois as questões e as reflexões construídas foram apreendidas de tal modo que se desdobraram em um aprofundamento reflexivo. Considero que a minha formação como pesquisadora foi engendrada nos momentos de deleite com a criação artística e, sobretudo, nas investigações em que a arte se entrelaça com o ato de educar, como narro neste artigo.

Dos processos vividos, procuro a atualização de certos traços marcados no percurso, bem como a produção de novos, nascidos a cada cruzamento de campos de saber e inseparáveis das escolhas feitas. Para essa narração, recorro a muitas lembranças. Lembranças que me proporcionam não apenas o reviver, mas o refazer, o reconstruir, o repensar as experiências de pesquisa do passado. Por mais nítida que a lembrança pareça, ela não é a mesma realidade vivida, porque não sou a mesma de então, já que há um percurso epistemológico em andamento e nele as ideias, as descobertas e as reflexões evoluíram.

Por que escolhi a narrativa neste artigo?

Penso que a narrativa é um modo de pensar e expressar que sempre anuncia um saber, pois ela se presta como princípio organizador que permite distinguir, compreender e representar a experiência humana. É, igualmente, um instrumento que gera significados a partir de relatos do subjetivo e do particular, pois comumente lembra o leitor outras narrações semelhantes, o que lhe permite "intercambiar experiências".

Walter Benjamin dá relevo à natureza prática da comunicação por meio da narrativa. Segundo esse filósofo, a narrativa 


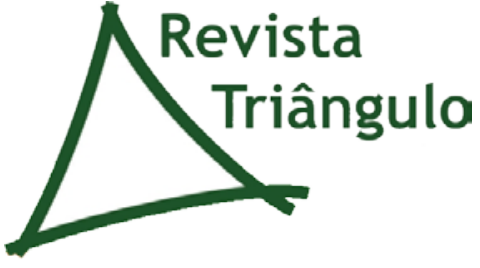

Uberaba, v. 5, n. 1, p. 87-105, jan./jun. 2012. ISSN: 2175-1609

[...] não está interessada em transmitir o 'puro em-si' da coisa narrada como uma informação ou um relatório. Ela mergulha a coisa na vida do narrador para em seguida retirá-la dele. Assim se imprime na narrativa a marca do narrador, como a mão do oleiro na argila do vaso (BENJAMIN, 1994, p. 205).

Os vestígios dos fatos vividos ficam presentes de muitos modos nas narrativas e, ao escolher esse modo de descrever as circunstâncias dos processos de leituras e pesquisa vividos, quero salientar as marcas que ficaram.

Escrevo, pois, não apenas para narrar alguma pesquisa realizada, mas para apresentar e discutir reflexões de ontem e de hoje sobre um processo de aprofundamento à questão: a arte compartilha a formação humana?

A referência para este texto é uma pesquisa sobre o sentido do vir-a-ser na criação artística de Pablo Picasso. A partir de alguns recortes dos estudos nela realizados, reflito sobre o conhecimento construído nessa trajetória de pesquisa que vai ganhando novas dimensões no continuum do tempo até agora, contribuindo para a identidade do que investigo.

\section{RIMAS E CORRESPONDÊNCIAS COM A OBRA DE PABLO PICASSO}

Sempre procurei trazer a beleza para dentro de mim. E em todas as aproximações com a arte, senti apreender tudo o que é belo, como se meu interior transformasse tudo em imagens de devaneio. O encontro com a arte de Pablo Picasso e a intenção de realizar uma pesquisa tendo por objeto a sua invenção artística é consequência natural das aproximações com a arte ao longo de minha vida.

Uma pesquisa sobre a criação artística de Pablo Picasso na área de educação? Na verdade, tal questionamento só teria significado para os que ainda acreditam que a discussão de educação restringe-se ao domínio cognitivista, à crítica de estruturas e processos do ensinar-e-aprender, ao exame de questões técnicas e ao domínio de disciplinas específicas, ditas pedagógicas. Procuro acompanhar o desenrolar de novas questões ao ato de educar e mesmo "re-visitar" os modelos clássicos de educação. E os temas que me comovem e me estimulam a repensar minha prática são os que consideram o mundo concreto que nasce dos sonhos, pois quando eles se concretizam, geram a beleza. E não seria um permanente abrir-se para o belo, o bem e o verdadeiro, a razão mais ancestral e o sentido mais atual da Educação? 


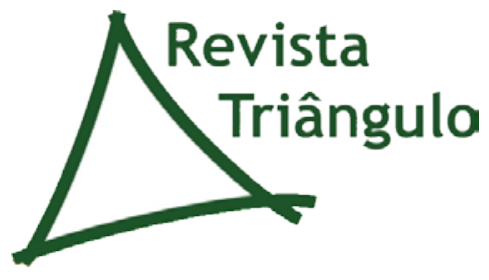

Uberaba, v. 5, n. 1, p. 87-105, jan./jun. 2012. ISSN: 2175-1609

Como me aproximo da criação dos artistas?

Escolho refletir a partir da arte e do homem sob o ponto de vista da philia (amor, amizade) segundo Chauí (1994, p. 13), da palavra filosofia. Muitos se esquecem de que no termo filosofia está incluída essa relação com o terreno da afetividade, expresso no radical do vocábulo. Essa é a dimensão do trabalho do filósofo com a qual me identifico: a base afetiva de sua reflexão. Como tal, sou amiga das expressões artísticas. Eu as interrogo com delicadeza de amiga. Torno-me silenciosa para ouvi-las. E depois, faço interrogações que pretendem ser muito vívidas, muito ternas, muito afetuosas pelo sentido das criações, tais como elas aparecem na realidade da obra de um artista como Pablo Picasso. Perguntei, pois, nessa dimensão filosófica da philia, o que a obra me contava, qual a sabedoria que ela e a vida de seu criador possuíam dentro de si.

Ao buscar o sentido da imagem dada por um mestre das artes plásticas, aproximei-me de uma proposta que se aproximaria de uma fenomenologia da beleza, ou, nas palavras de Bachelard (1993, p.2), uma "fenomenologia da imaginação", pois procuro trazer à luz a tomada de consciência de uma pessoa maravilhada pelas imagens da pintura. Essa postura fenomenológica levou-me a buscar as imagens criantes do artista e a compreensão da linguagem poética. Com o filósofo do devaneio aprendo que "o que constitui o centro da relação com o mundo é a maneira como a natureza aparece à consciência, sobretudo, por meio dos escritos dos poetas, [pintores] e prosadores sensíveis a ela” (ABREU-BERNARDES, 2010, p. 207). Um fenomenólogo profissional exigiria, certamente, bem mais do que isso. Permanecer em situação filosófica, na dimensão da philia, buscar como parceiros artistas e filósofos para pensar a partir da arte são talvez descrições mais fiéis ao que pretendi desenvolver neste estudo.

Os estudos sobre a obra do pintor espanhol abrangeram as primeiras tentativas de eliminar limites disciplinares. Pensar a filosofia por meio de Pablo Picasso foi um caminho que, se parece estranho e inseguro para alguns, para mim foi uma experiência de abrir a mente ao entendimento, em que me aventurei a deixar interagir pensamentos e imaginação. “Ocorre sempre assim: na ordem da filosofia, só se persuade sugerindo sonhos fundamentais, restituindo-se aos pensamentos suas avenidas de sonhos” (BACHELARD, 1998, p. 4). 


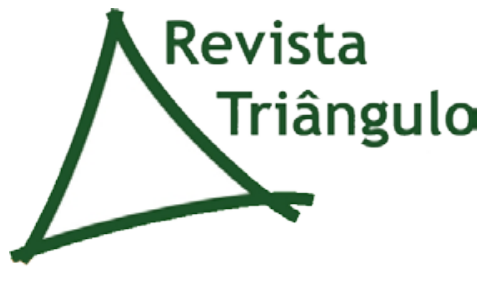

Uberaba, v. 5, n. 1, p. 87-105, jan./jun. 2012. ISSN: 2175-1609

A opção por duas formas de expressão humanas diferentes, a conceitual e a artística, e por caminhos diversos, porém em torno de um mesmo núcleo temático, permitiu-me colocar em pauta a possibilidade de fazer afluir expressões e formulações de saberes, para o melhor entendimento do sentido de mudança na obra de um artista. A convergência de olhares e de linguagens, a construção de um pensamento mais totalizante e integrativo, pareceu-me amplamente oportuno. Nessa acepção integradora, Nietzsche, em “A filosofia na época trágica dos deuses” (1974, p. 44), apresenta um questionamento: "será que este mundo está cheio de culpa, de injustiça, de contradições e de sofrimento? Sim, grita Heráclito, mas só para o homem limitado que vê as coisas separadas umas das outras e não no seu conjunto”. Uma escuta atenta, um olhar interessado permeou a busca de uma visão de conjunto.

Entendo que neste trabalho desenvolvi um pensamento filosófico sobre a arte direcionado à educação, aproximando-me de um horizonte transdisciplinar. Para essa afirmação, baseio-me em eixos que nortearam a pesquisa: nela, de certa maneira, procurei confrontar uma lógica racionalista com minha intuição, afeição e sensibilidade. Busquei, assim, enriquecer os meus pensamentos, tornando-os pessoais, afetivos e teóricos. Ao indagar o sentido do fluir, da transitoriedade, da mudança na obra de Pablo Picasso, deixei que a sensibilidade apontasse para um refletir diferente. O compromisso crítico com o pensar não me fez deixar de lado a emoção. Isso porque pensava e sentia (ainda hoje isso ocorre) que dentro de mim tudo se integrava: a afeição, a intuição, a lógica, a inteligência, os instintos, os impulsos e os saberes.

Vários pensadores têm acentuado a necessidade de que eduquemos nosso olhar para a percepção de um horizonte aberto, no qual cada área de conhecimento seja vista como um universo, cujo centro pode deslocar-se segundo a indagação de quem o focaliza. Não é uma tentativa de abarcar o máximo de extensão possível num mesmo olhar, mas um contemplar que faz convergir o movimento de vários territórios do saber, aqueles que se abrem à aventura desse encontro. No caso desse estudo, tratava-se de buscar essa postura investigativa de abrir um espaço de respiração para a circulação de ideias e de emoções, uma atitude de ampliação de horizontes e uma "re-leitura” de conceitos.

Ao relatar a experiência de pensar a partir da emoção sentida diante da beleza da criação artística, procurei não somente a experiência de superar fronteiras, mas de aproximar- 


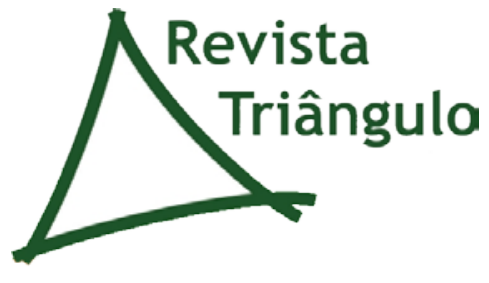

Uberaba, v. 5, n. 1, p. 87-105, jan./jun. 2012. ISSN: 2175-1609

me do mundo que nasce dos sonhos: a arte. Desejei percorrer o caminho do prazer, que tanta falta faz na motivação do ambiente escolar. E, nesse contexto, quis compreender o sentido da mudança contínua na inventividade do mestre espanhol ao longo de sua vida. Analisei suas obras, o que elas me diziam, o que se transformava nas múltiplas telas, esculturas, gravuras, desenhos e outras manifestações artísticas.

O olhar investigativo para as múltiplas expressões que a imaginação de Pablo Picasso compôs deixou-me mais interessada no trajeto temático, na viagem imaginária do pintor espanhol do que na criação final das obras que ele cunhou. Reflito que em nossa sociedade o sentido da experiência artística é encontrado, sobretudo, na obra final, desconsiderando-se totalmente os processos de invenção, já que o produto final pode tornar-se mercadoria e distanciar-se de seu autor, reduzindo-se a um objeto a ser negociado, enquanto a composição em si é liberdade. Entretanto, criar é essencialmente um processo, um caminho de crescimento para aprender, conhecer e, ainda, compreender-se e realizar-se naquilo que cada um traz de melhor em si como potencialidade singular.

Em visita a uma exposição de Pablo Picasso, uma tela chamou-me atenção "Fazendeira e nu, rodeada de galinhas” (1938). A imagem trazia de modo mais evidente os traços iniciais de seu processo de criação. As linhas que se sobrepunham indicavam as tentativas, as intuições, o caminho percorrido. O mestre da pintura apresentava a todos os espectadores como tinha criado as potencialidades que se realizaram e um convite para prosseguir a atividade imaginária. E como em muitas outras criações, a figura humana estava presente $^{\mathrm{iv}}$.

A análise das obras dessa exposição somou-se às leituras realizadas no processo investigativo. Em todo o percurso, a pesquisa realizada voltou-se para a interpretação das criações artísticas de Pablo Picasso, tendo como mediação a sensibilidade que se abre diretamente à sua arte.

Para refletir sobre o sentido do devir, li fragmentos de Heráclito e alguns comentadores, como transcrevo a seguir:

Em Crátilo lê-se: "Heráclito diz algures que tudo está em mudança e nada permanece imóvel, e, ao comparar o que existe com a corrente de um rio, diz que se não poderia penetrar duas vezes no mesmo rio. A metáfora do rio foi utilizada por 


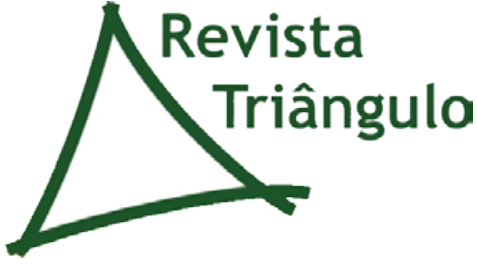

Uberaba, v. 5, n. 1, p. 87-105, jan./jun. 2012. ISSN: 2175-1609

Heráclito para enfatizar a total continuidade da mudança: pànta rei, tudo flui, tudo se move sem cessar, tudo é vir-a-ser. [...] A realidade é o fluxo contínuo dos opostos; a estabilidade é ilusória, o devir, a multiplicidade em mudança é o real. O que importa é a própria existência que sem cessar flui e o entendimento de que todas as coisas se reduzem à unidade, pois o um é afinal o múltiplo. (Fr. 50, Hipólito Ref. IX, 9, 1, apud KIRK e RAVEN, 1994, p. 193-202).

O fluxo contínuo dos seres não ocorre de modo caótico, pois sob os contrários em luta, sob o devir, está essa unidade.

O que refleti a partir de uma leitura cruzada de Heráclito-Pablo Picasso, tão ousada, segundo comentários de interlocutores daquela época? Entendi que as cosmovisões do artista e do filósofo diferem, e o próprio conceito de devir possui, portanto, conotações diferentes. Heráclito preocupa-se com o real, busca explicar a realidade em seu sentido de harmonia, que, para ele — e aí está a sua grande contribuição — , é a harmonia dos contrários. A vocação de Heráclito é metafísica.

O pintor espanhol não procura traduzir, como Heráclito, o processo cósmico das transformações, mas expressar as nuances da realidade que o seu olho vê. Se o devir de Heráclito refere-se ao cosmos, o entendimento que está presente no tempo de Pablo Picasso é o ver que apreende todos os possíveis fragmentos e mudanças do espaço. O mestre das artes volta-se para o movimento do ver, para a percepção. Pablo Picasso busca traduzir o efêmero da existência humana.

Pergunto-me: o que via na criação artística de Pablo Picasso? Por que a olhava como pessoa ávida de reflexões que já se deixara render ao que via, do ponto de vista afetivo, do ponto de vista emocional, do ponto de vista sentimental, à beleza do quadro? Além da beleza, qual é o saber sobrante que me encaminhava para uma direção em que tem sentido a pergunta reflexiva? Além do belo, além da beleza, o que de sabedoria, o que de sophia ensinavam-me os desenhos? O que me instruíam as suas telas e as esculturas? Sabia que deveria olhar profundamente, não apenas as aparências, a visibilidade, a combinação, a composição, os traços, as linhas, as oposições cromáticas e as somações estéticas que a obra contém em si, mas também lançar minhas perguntas ao próprio objeto, ao próprio tema, ao próprio assunto. Estava certa de que precisaria dialogar com as invenções do mestre espanhol para, em seguida, fazer a minha pergunta de um modo que houvesse um sentido no seguir um caminho mais longo e alcançar o próprio artista que as criou. 


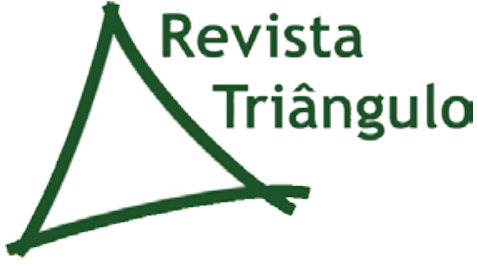

Uberaba, v. 5, n. 1, p. 87-105, jan./jun. 2012. ISSN: 2175-1609

A apreciação da obra incluía a mim, quando deixava de me ocultar e de me dissimular, tentando uma objetividade e uma neutralidade. Baseada nesses princípios, a minha própria subjetividade foi assumida como uma forma de construir um conhecimento. Lembro-me também das leituras que fazia sobre como deveria interpretar a arte de Pablo Picasso. Sabia que não seria uma aproximação semelhante à de um crítico de arte — que não sou — mas que deveria possibilitar o envolvimento desejado.

Sentir a arte e não procurar o seu significado por meio de algo exterior a ela, por meio de uma interpretação, mas buscar compreender o que a criação do artista diz à sensibilidade, eis o que procurei realizar ao analisar as obras de Pablo Picasso. Não recorri, portanto, ao que me diziam os críticos e as teorias sobre a arte, mas procurei a vivência pessoal da criação artística como o que me diz algo, por meio de um abrir-se diretamente à minha sensibilidade diante dela.

Esse sentido de interpretação, ou de “contra interpretação” (SONTAG, 1987, p. 14) da arte é o que me tem norteado. Para as ideias que elaboro a partir da pintura, da música, da poesia, da linguagem artística, enfim, percorro o caminho proposto pela filósofa norteamericana, marcado pelo receio diante da possibilidade do escrutínio crítico de imiscuir-se no poder mágico da arte.

Segundo esses princípios, o que testemunhei na múltipla criação de Pablo Picasso?

Vi o homem sofrido, a mulher abraçando o filho, o saltimbanco, a vítima da guerra, a mulher chorando, o toureiro, o velho solitário, a mulher sonhando. Dos rostos, dos gestos, das cenas e cenários observados, concluí que uma das leituras possíveis da criação desse artista é que o vir-a-ser, a meu ver antropológico, ou mais precisamente existencial, dos seus temas, estilos, modelos, cores e técnicas expressa esteticamente uma obsessão pela pessoa ou pelo sentido do humano. Pablo Picasso usava suas criações artísticas para traduzir seu comprometimento com a condição do homem. Essa é a unidade que existe sob a multiplicidade de sua obra.

Em reflexões de hoje, observo que as criações do pintor espanhol expressam ora um ver político, solidário e humanista, ora um deslumbramento pelo mundo criador de novas realidades e de novos sentidos. A arte, assim como sua vida, é variada, surpreendente e afoita. 


\section{Revista
Triângula}

Uberaba, v. 5, n. 1, p. 87-105, jan./jun. 2012. ISSN: 2175-1609

É o signo plástico de uma existência vivida intensa e criativamente até os noventa e um anos de idade.

Penso, no entanto, que seria um erro ver a obra de Pablo Picasso apenas como uma autobiografia pintada. Isso porque ele sempre transcendeu o pequeno domínio de suas aventuras pessoais, dos acontecimentos históricos e dos grandes amores vividos, elevando-os ao atemporal e universalmente humano. A arte que eu apreciava expressava o fluir de sentimentos diante de fatos, pessoas, acontecimentos, sem sucumbir a uma interconexão mecânica entre o mundo em que viveu e sua expressão artística.

Ao analisar como Pablo Picasso concedia à imaginação todos os meios de expressão, todas as imagens materiais que se produziam em seus devaneios, aproximei-me do estudo do conceito de imaginação material de Gaston Bachelard. Imaginação e razão constituem, para esse filósofo, o pensamento filosófico-científico e poético em sua tencionalidade dinâmica. E se a via racional propõe uma cisão entre as ideias, os conceitos e o imaginário, pela via onírica se tangem, se unem mutuamente; não são sobrepostos, mas complementares em suas diferenças. O filósofo da imaginação criadora percorre o universo dos sonhos e devaneios, buscando apreender o ser em sua originalidade, iluminar a consciência e registrar a polifonia dos sentidos que despertam e se harmonizam no devaneio poético. Nesse sentido, uma concepção do real que não se interessar pelo onírico despoja-se de alguns dos interesses que conduzem ao conhecimento.

\section{O QUE A OBRA DE PABLO PICASSO ENSINA AO EDUCADOR}

E ao meditar sobre essas leituras, indago: e o educador, como concebe seu trabalho de formação do homem? Há aproximações com o labor do artesão, com a lida dos poetas, dos pintores, dos músicos, dos escultores e dos dançarinos? O que o educador aprende com os artistas?

Existem intelectuais que se envergonham das mãos e das atividades laboriosas. O artista, ao contrário, desconsidera os preconceitos e pelo seu arte-fazer testemunha vivencialmente o significado humano do trabalho. Os gestos das mãos dos artistas, alçados à dimensão do símbolo, representam a consciência do fazer e do criar a partir de um devaneio. 


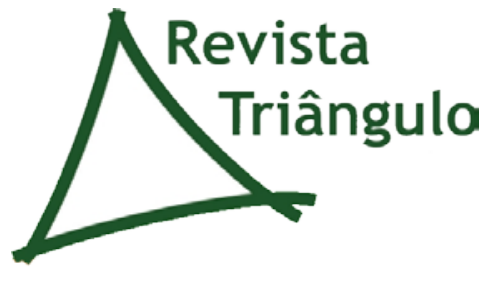

Uberaba, v. 5, n. 1, p. 87-105, jan./jun. 2012. ISSN: 2175-1609

Há uma sabedoria manual na experiência única do artista que engendra a beleza e que nos traz um amplo campo de reflexão. É a expressão da liberdade e da transgressão. O educador que se aproxima da dimensão estética, não por meio dos livros, mas por meio do diálogo com a linguagem, baseada na experiência dos próprios artistas, modifica o gesto pedagógico. Após um encontro mais íntimo com Dionísio, demuda-se o campo educacional que não é apenas educativo, e muito menos escolar. Transforma-se o trabalho do educador que observa o gesto transgressor e sensível do artista.

O conhecimento construído a partir da obra de Pablo Picasso talvez possa resumir-se na afirmação de que a arte é outro modo de conhecer a realidade, e o trabalho do educador poderá tornar-se mais denso, mais criativo, mais sensível e mais amplo se alcançar esse sentido da criação artística e apreender seus valores. O contato com a arte e o sentimento estético traz um resultado transcendental. Ele é a beleza, e hoje eu a reconheço não apenas nas criações dos poetas, dos músicos, dos escultores, dos bailarinos ou dos fotógrafos, mas a encontro no próprio ato de criação humana.

Além disso, a obra do pintor espanhol questiona e estimula a indagação. Nesse contexto, o artista ensina a constante busca, a atitude crítica, inovadora, transgressora e de ruptura. Quando penso em uma universidade crítica e não produtivista, observo os ensinamentos dos artistas. Se quisermos formar educadores que superem a mera transmissão de informações, a erudição formal e distante, a transposição de conhecimentos, e que sejam educadores que estimulem o pensar e o sentir, precisamos nos aproximar dos que, em uma dimensão mais humanista, expressam não só a beleza, mas os valores densos, ambivalentes e polissêmicos que a arte nos proporciona.

Apesar de ter recebido toda a formação escolar sob a hegemonia do cognitivo, penso a educação hoje como um empreendimento muito mais amplo, que envolve emoções, imaginação e sensibilidade. A perspectiva que deve animar a educação é a que remonta também à verdade, à beleza e à moralidade, além de considerar as dimensões política, cultural e pedagógica presentes nas teorias e nas práticas educativas. Se a educação não tiver essas faces, corre o risco de ser ineficaz ou de ser eficazmente desumana. 


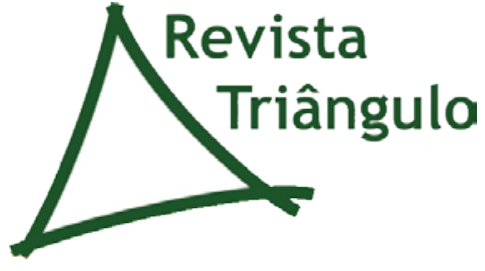

Uberaba, v. 5, n. 1, p. 87-105, jan./jun. 2012. ISSN: 2175-1609

\section{CONSIDERAÇÕES FINAIS}

É em um cenário de realidades conceituais, poéticas e artísticas, das quais Pablo Picasso provavelmente teve mais consciência do que qualquer outro artista de sua época, que se deve entender o conceito de homem e de mundo que ele expressa em sua obra. Um mundo caótico, fugaz, que contesta os paradigmas na arte e na literatura, enaltece a liberdade e que também é, muitas vezes, poético, erótico e metafórico. Um mundo também de muitos conflitos políticos, ideológicos e econômicos. Época de guerras, de novas perspectivas no âmbito das ideias, como a fenomenologia, a psicanálise, o marxismo e a teoria da relatividade. Ele conseguiu captar em sua obra aquilo que a cosmovisão de seu tempo tinha de mais significativo: a desconstrução. Não é possível enquadrar Pablo Picasso em um movimento, porque ele é exatamente a ruptura.

A arte nos ensina esse poder de transgressão que aparece de uma forma negativa e que do lado positivo é a liberdade do ser. O artista é um gesto de transgressão. A Arte é exatamente isso, ou ela vira uma receita, pedaços de uma coisa que constrange.

Toda a experiência vivida durante o processo de devaneio e estudo, todas as leituras e o convívio artístico tornaram-se estímulo para embasar questões que se aprofundaram e que emergem das reflexões construídas. Tais perguntas referem-se às interações entre arte e educação, à compreensão da arte como conhecimento e ao sentido da educação da sensibilidade, dimensão minimizada no ato educativo em nossas escolas. Pensar a educação por meio de Pablo Picasso foi, para mim, uma experiência de abrir a mente ao entendimento de que o artista calibra o gesto pedagógico.

Notas:

\footnotetext{
' O texto original deste artigo foi apresentado na $27^{\mathrm{a}}$ Reunião Anual da Associação Nacional de Pós-Graduação e Pesquisa em Educação - ANPEd, Caxambu, MG, 2004.

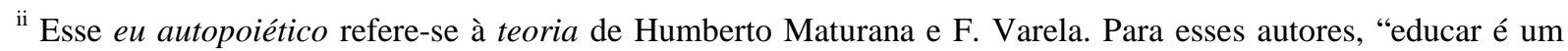
fenômeno psicossocial e biológico que envolve todas as dimensões do ser humano, em total integração do corpo, da mente e do espírito. [...]. Essa teoria ajuda a fundamentar a construção interativa do pensar e sentir, oferecendo uma base científica de grande consistência epistemológica, capaz de reconciliar o processo de construção do conhecimento e a maneira dinâmica na qual a vida acontece" (Maturana e Varela, 1980, apud MORAES e TORRE, 2004, p. 55).

iii Como não tenho a pretensão de elaborar uma investigação fenomenológica "pura", mas de aproximar-me dela, permito-me, nesse momento, partir de pensadores que não se identificam como fenomenólogos, embora
} 


\section{$\bigwedge_{\text {Triângulo }}^{\text {Revista }}$}

Uberaba, v. 5, n. 1, p. 87-105, jan./jun. 2012. ISSN: 2175-1609

apresentem semelhanças conceituais, pelo menos nessas reflexões.

${ }^{\text {iv }}$ Fui além dos livros, pois uma leitura da própria obra de Pablo Picasso foi realizada, constituindo-se etapa da pesquisa. Tal investigação realizou-se durante a exposição Picasso anos de guerra: 1937-1945 (Rio de Janeiro, 1999). Mais tarde, essa experiência se repetiria com Picasso na Oca: uma retrospectiva (São Paulo, 2004), no Museu Rainha Sofia, em Madri (2012), e no Museu Picasso, em Barcelona (2012).

\section{REFERÊNCIAS}

ABREU-BERNARDES, S.. As dimensões estética e política da formação de professores para a rede pública municipal de Uberaba - MG. Práxis Educativa, Ponta Grossa, 5, p. 205-212, dec. 2010. Disponível em:

$<$ http://www.revistas2.uepg.br/index.php/praxiseducativa/article/view/1312/1395>. Acesso em: 03 fev. 2012.

BACHELARD, G.. A Poética do devaneio. São Paulo: Martins Fontes, 1996a.

- A formação do espírito científico: contribuição para uma psicanálise do conhecimento. Rio de Janeiro: Contraponto 1996b.

A poética do espaço. São Paulo: Martins Fontes, 1993.

. A água e os sonhos: ensaio sobre a imaginação da matéria. São Paulo: Martins Fontes, 1998.

BENJAMIN, W.. Magia e técnica arte e política. In: Obras escolhidas. 7. ed. São Paulo: Brasiliense, 1994.

BOSI, E.. Memória e sociedade: lembranças dos velhos. 3. ed. São Paulo: Companhia das Letras, 1994.

CHAUÍ, Marilena. Introdução à História da Filosofia: dos pré-socráticos a Aristóteles. São Paulo: Brasiliense, 1994.

HEIDEGGER, M.. De camino al habla. Barcelona: Edicionaes del Serbal, 1987.

KIRK, G. S.; RAVEN, J. E.; SCHOFIELD, M.. Os filósofos pré-socráticos: história crítica com seleção de textos. Lisboa: Fundação Calouste Gulbenkian, 1994.

LARROSA, J.. Notas sobre a experiência e o saber da experiência. Revista Brasileira de Educação, Rio de Janeiro, n.19, p.20-28, jan.-abr. 2002.

MEIRELES, C.. Poesia completa. Rio de Janeiro: Nova Aguilar, 1994. 


\section{Nevista}

Uberaba, v. 5, n. 1, p. 87-105, jan./jun. 2012. ISSN: 2175-1609

MERLEAU-PONTY, M.. De Mauss a Claude Lévi-Strauss. In: . Merleau-Ponty. São

Paulo: Abril Cultural, 1980. (Coleção Os Pensadores).

MORAES, M. C. e TORRE, S. de la. Fundamentos e estratégias para reencantar a educação. Petrópolis: Vozes, 2004.

NIETZSCHE, F. W.. A filosofia na época trágica dos deuses. In: Obras

incompletas. Seleção de textos de Gérard Lebrun. Tradução e notas de Rubens Rodrigues Torres Filho. São Paulo: Abril Cultural, 1974.

PICASSO, P.. Fazendeira e nu, rodeada de galinhas, 1938. In: Picasso anos de guerra: 193719454. [Dominique Dupuis-Labbé (Curadora francesa); Agnaldo Farias (curador brasileiro); tradução do texto francês por Irene Paternot]. Museu de Arte Moderna do Rio de Janeiro. São Paulo: Brasil Connects Cultura \& Ecologia, 2004.

PICASSO NA OCA: uma retrospectiva. [Dominique Dupuis-Labbé (Org.); tradução do texto francês por Paulo Neves e Beatriz Toledo da Rocha e Silva]. Oca, Parque Ibirapuera. — São Paulo: Brasil Connects Cultura \& Ecologia. 2004.

RILKE, R. M.. Poemas. Seleção, tradução e introdução de José Paulo Paes. São Paulo: Companhia das Letras, 1993.

ROSA, J. G.. Grande Sertão: Veredas. 19. ed. Rio de Janeiro: Nova Fronteira, 2001.

SONTAG, S.. Contra a Interpretação. Porto Alegre: L\&PM, 1987. 